Int. J. Electrochem. Sci., 11 (2016) $8256-8269$

International Journal of

ELECTROCHEMICAL

SCIENCE

www.electrochemsci.org

\title{
Corrosion Protection of Stainless Steel by Triethoxyoctylsilane and Tetraethoxysilane
}

\author{
Karol Szubert ${ }^{1, *}$, Jarosław Wojciechowski ${ }^{2}$, Joanna Karasiewicz ${ }^{1}$, Hieronim Maciejewski ${ }^{1}$, \\ Grzegorz Lota ${ }^{2, *}$ \\ ${ }^{1}$ Adam Mickiewicz University, Faculty of Chemistry, Umultowska 89b, 61-614 Poznan, Poland \\ ${ }^{2}$ Poznan University of Technology, Institute of Chemistry and Technical Electrochemistry, \\ Berdychowo 4, 60-965 Poznan, Poland \\ *E-mail: karolszu@amu.edu.pl, grzegorz.lota@put.poznan.pl
}

doi: $10.20964 / 2016.10 .05$

Received: 23 June 2016 / Accepted: 25 July 2016 / Published: 6 September 2016

Different methods of silane coating deposition on the surface of 304 stainless steel were studied. Deposition was performed in different solutions with a variety of $\mathrm{pH}$ values. Three types of solutions were prepared i.e. neutral, containing only methanol with triethoxyoctylsilane and two acidic consisting of methanol, triethoxyoctylsilane, tetraethoxysilane and hydrochloric acid which was used to establish $\mathrm{pH}$ values equal to 1 and 3.5. Surface electrochemical analysis carried out using a $3.5 \mathrm{wt} \%$ $\mathrm{NaCl}$ solution and several common techniques including corrosion potential monitoring at open circuit conditions, linear polarization and electrochemical impedance spectroscopy tests showed that the way in which silane solution is prepared and silane coating is deposited is heavily influencing on the type of corrosion inhibition. Additionally, spectroscopic methods were employed. Due to oxide passive film on the steel surface, metal-O-Si bonds are formed, thus creating an intermediate layer between the oxide layer and the outermost siloxane layer (Si-O-Si). Furthermore, a long aliphatic chain of triethoxyoctylsilane compound increases steel surface hydrophobicity.

Keywords: Corrosion protection, Linear polarization, Organosilicon coatings, Stainless steel

\section{$\underline{\text { FULL TEXT }}$}

(C) 2016 The Authors. Published by ESG (www.electrochemsci.org). This article is an open access article distributed under the terms and conditions of the Creative Commons Attribution license (http://creativecommons.org/licenses/by/4.0/). 